\title{
A Brief Introduction to Han Fu and Han Dynasty Architectural Culture
}

\author{
Yang Yang \\ School of Architecture, Tianjin University, Tianjin, China
}

\section{Email address:}

2823291047@qq.com

\section{To cite this article:}

Yang Yang. A Brief Introduction to Han Fu and Han Dynasty Architectural Culture. Science Discovery. Vol. 9, No. 5, 2021 , pp. $239-243$. doi: 10.11648/j.sd.20210905.17

Received: September 10, 2021; Accepted: October 8, 2021; Published: October 19, 2021

\begin{abstract}
The Han Dynasty was in the rising stage of China's feudal society, with a strong state, prosperous economy and developed culture. During this period, there were many types of architecture and magnificent scale. Although recorded in historical documents, they are brief and scattered. In comparison, the most perfect display is indeed the Han Dynasty rhetoric. $\mathrm{Han} F u$ is a kind of rhymed prose that emerged in the Han Dynasty, the so-called poetry and song, Fu is an independent genre in traditional Chinese literature. Despite the fact that there is no surviving Han Dynasty architecture, its main features can be glimpsed from the representative works of $\mathrm{Han} \mathrm{Fu}$. By virtue of their respective lives, the Hanfuists have truly reproduced the appearance of ancient architecture and revealed its cultural connotations, leaving extremely valuable architectural historical materials for future generations. From the existing Han Dynasty rhetoric, the portrayal of the capital city and its buildings take an important place. The article selects the representative works of capital cities and palaces in the Han fugue as the object of study. Through the depiction of cities and buildings in the fugue, it analyzes the characteristics of city building and architectural style in the Han Dynasty, highlighting the value and significance of architecture in the Han literati.
\end{abstract}

Keywords: Han Dynasty, Han Fu, The Han Dynasty Architectural

\section{汉赋与汉代建筑文化简述}

\author{
杨洋 \\ 天津大学建筑学院, 天津市, 中国
}

\section{邮箱}

2823291047@qq.com

摘要：汉朝处在中国封建社会的上升期，国家强盛，经济繁荣，文化发达。在这一时期，有许多类型的建筑和宏伟的 规模，史书文献虽有记载却显简略而零散。相比之下，展现最为完美充分的却是汉代辞赋。如今，尽管没有现存的汉 代建筑, 但汉代建筑的特点可以在汉赋作品中窥见二二。从现存的汉代修辞学来看, 京城及其建筑的形象占有重要的 地位。本文选取汉赋中都城赋和宫殿赋的代表性作品作为研究对象, 通过其中对城市和建筑的描写, 分析汉代城市建 筑和建筑风格的特点, 突出建筑在汉代文人中的价值和意义。

关键词: 汉代, 汉赋, 汉代建筑, 建筑文化 


\section{1. 引言}

汉赋是在汉朝涌现出的一种有韵的散文, 所谓诗词歌 赋, 赋是我国传统文学中一种独立的文体, 是汉代文学之 代表, 领汉百载之风骚。汉赋大家班固在其大作《两都赋》 序中提到“赋者, 古诗之流也。”汉赋“体兼众制, 文备多 方”[1], 垂文扬彩, 体物写志, 佳篇甚多, 传世千古。在 人类亿万斯年的时光里, 汉赋就同唐诗、宋词、元曲、明 清小说一样闪耀在中国传统文学史中。王国维曾云: “凡 一代有一代之文学: 楚之骚, 汉之赋, 六代之骄语, 唐之 诗, 宋之词, 元之曲, 皆所谓一代之文学, 而后世莫能继 焉者。”[2]

汉代是中国古代建筑史上的繁荣时期, 赋家借由描绘 建筑来进行创作, 达到表达情感、讽棟君王, 或教化世人 的目的。虽然在汉赋中以建筑为描写对象的作品大多夸饰, 但它那铺陈体物的基本手法是写实的, 因而汉赋家凭借各 自的生活经厉亲身目睹的感受, 真实地再现了古代建筑的 风貌, 并揭示其文化内涵, 为后人留下了极为珍贵的建筑 史料。

田胜利在《汉赋中长安、洛阳建筑名物命名的文化义 涵选释》[3]认为汉朝西都长安的建筑命名体现古代的仙道 文化和生命意识, 而东都洛阳则富有德礼文化和方位意识, 两大都城的命名差异, 是两种帝都气象的彰显。根据章沧 授在《论汉赋对建筑文化的阐释》[4]统计, 以建筑为对象 的汉赋有 20 余篇、并将其分为以下几类:都市建筑, 宫殿 建筑、园林建筑、观阙台馆建筑; 周显在《汉赋中的建筑 认知》 [5]中以 《鲁灵光殿赋》为研究对象, 研究其中描写 建筑的方式在历史过程中的继承变化过程, 通过与现代描 写评论建筑的方式对比, 总结汉赋建筑描写之特色; 邱杨 琰《从汉代京都赋看两汉都城建筑文化》 [6]以京都大赋为 主要研究对象, 利用京都赋百科全书的特性解析两汉京都 建筑的信息; 各风华《论建筑风俗对汉赋的影响》[7]认为 风水术的流行使汉赋中的建筑描写体现出一些风水观念, 如法天则地、仿生象物的流行使赋家特别重视对建筑物象 征性特点和意蕴的表述; 贡小妹《两汉建筑赋的环境描写》 [8]汉代建筑赋中的环境描写展示了汉代人对自然的矛盾 态度: 既敬畏, 又热爱; 既顺应也利用; 既渴望占有, 又 将对神仙世界的向往寄托于自然; 龙坚毅《汉赋与汉代社 会》[9]析取汉赋关于社会经济、宗教思想、文化艺术等方 面的内容, 多角度阐述了汉赋视野中的汉代社会。

汉代建筑虽无遗物, 却可从从《汉赋》的代表作品中 可窥探其主要特点。本文选取汉都城赋和宫殿赋中集大成 者来陈述汉代文人对于汉代建筑文化的认知:

都城赋: 班固《两都赋》(《西都赋》《东都赋》) , 张衡《二京赋》 (《西京赋》《东京赋》)

宫殿赋: 扬雄《甘泉赋》，王延寿《鲁灵光殿赋》[10]

\section{2. 汉赋中描绘的汉代建筑特点}

\section{1. 恢弘的群体空间组合}

汉代宫殿建筑的营造真正达到了华靡伟大、空前绝后 的地步, 西汉之初开始建造长乐宫、未央宫、建章宫等大
型宫殿数座, 《西都赋》列数其“离宫别馆, 三十六所”之 众多。宫殿内部空间纵横交错, 形成庞大恢弘的群体空间 结构, 《西都武》所述未央宫和建章宫足以令人骇目, “徇 以离宫别寝, 承以崇台闲馆, 焕若列宿, 紫宫是环。清凉 宣温, 神仙长年, 金华玉堂, 白虎麒麟, 区宇若兹, 不可 殚论”，仅未央宫就有十几组宫殿组成。

宫殿占地极广, 据载西汉长安城内仅长乐、未央两处 宫殿即占据全城面积的二分之一。如再加上明光宫、桂宫、 北宫等宫殿, 宫殿区约占全城面积的三分之二。[11]与长 安相似, 东汉洛阳城的宫殿占面积约为全城的一半。主要 宫殿南宫和北宫, 分别位于城南与城北的中部, 占全城面 积十分之一, 据张衡《东京赋》记载, 光洛阳宫城内北宫 中的“德阳殿”便“周旋容万人, 陛高二丈”。可见其面积庞 大，气势恢弘。

不仅如此, 宫殿之间往往用飞阁围廊相连结成一个整 体, 班固《西都赋》中有载“槷路经营, 修除飞阁。自未 央而连桂宫, 北弥明光而亘长乐, 凌隥道而超西墉, 掍建 章而连外属, 设璧门之风阙, 上触棱而栖金爵。”张衡《西 京赋》的描述则更加直白: “长廊广庹, 途阁云蔓。闰庭 论异, 门千户万。”以飞阁栈道为交通, 可以从未央宫到 达桂宫、长乐诸宫, 再用“蹬道”连结城外的建章宫。这种 延续性的空间群体组合成千门万户的宫殿建筑群。

这种情况不止发生在京都, 王延寿《鲁灵光殿赋》所 写藩王鲁恭王亦追求“于是乎连阁承宫, 驰道周环。阳榭 外望, 高楼飞观。长途升降, 轩槛曼延。渐台临池, 层曲 九成。屹然特立, 的尔殊形。高径华盖, 仰看天庭。飞陛 揭拿, 缘云上征。中坐垂景, 煩视流星。千门相似, 万户 如一。岩窔洞出, 逶迤诘屈。周行数里, 仰不见日。”凭 廊上栏杆四周眺望, 感觉天地广阔无垠。

\section{2. 奇巧的木架结构}

\subsection{1. 斗拱的普遍使用}

斗拱是中国传统建筑构造的最大特色, 在汉代, 斗拱 已经普遍使用。《鲁灵光殿赋》中载“层栌磥垝以苃峨, 曲枅要绍而环句”, “云栥藻棁”, “白鹿子蜺于欂栌, 蟠螭 宛转而承椐”。其中“栌”“曲枅”, “盗”, “楛栌”皆是“斗拱” 之意, 扬雄《甘泉贼》中亦有描述: “击薄栌而将荣”“登

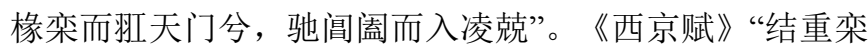
以相承。”其中的“栌”为“斗”, “栾”为“拱”[12]。

\subsection{2. 屋檐出挑, 凌空飞动}

《西都赋》中描绘“上反宇以盖戴, 激日景而纳光”, 檐脊“层构厥高”，作为中国古代建筑特色之一的屋顶，在

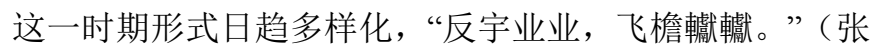
衡《西京赋》) 。屋檐出挑凌空飞动, 笼罩屋宇, 宫殿光 彩外露, 与日光互相辉映。这种结构不仅是汉代宫殿建筑 的共同特征，亦构成了中国古代建筑的基本模式。

\subsection{3. 抬梁式建筑的成熟}

汉代建筑的木结构主要是抬梁式, 当时的技术己经解 决了木质结构的承重问题, 以达到“屋不呈材, 墙不露形” 的目的。班固《西都赋》中描述未央宫“因瑰材而究奇, 
抗应龙之虹梁。列棼橑以布翼, 荷栋桴而高骧。”扬雄《甘 泉赋》“历倒景而绝飞梁兮, 浮蠛蠓而敉天”, 张衡《西京 赋》“亘雄虹之长梁”。其中的“虹梁”“飞梁”“棼”“栋桴”便 是层叠中的各种梁式。扬雄《甘泉赋》: “大厦云谲波诡”, 构造精巧多变 [13]。

王延寿的《鲁灵光殿赋》对抬梁式木结构的描写则更 加细致。“于是详察其栋宇, 观其结构。规矩应天, 上宪 觜陬。倔佹云起, 缼峑离搂。三间四表, 八维九隅。万楹 丛倚, 否砢相扶。浮柱岩滞以星悬, 漂峣嵲而枝拄。飞梁 偃寒以虹指, 揭蓫鿪而腾凑。层栌磥垝以苃峨, 曲枅要绍 而环句。芝栭欑罗以践乍, 枝掌权枒而斜据。傍天蟜以横 出, 互䵢纠而搏负。下岪蔚以璀错, 上崎嶬而重注。捷猎 鳞集, 支离分赴。”栌聚在一起, 梁上交木参差斜依。斗 拱伸张开来, 既相连又一根随一根从旁横出, 负载着大梁, 形状弯曲壮丽而文饰繁杂。众木“纵横骆驿, 各有所趣”, 层层叠叠, 而构成完整的抬梁式木架结构体系, 这是对其 建筑结构的精准描述。

\section{3. 高大的建筑体态}

高台建筑自春秋时期开始发端, 盛行于战国时期, 进 入汉代, 已经是高台建筑发展的黄金时期, 并且向着 “观”“阙”的方向发展。据文献记载, 长安未央宫高三十五 丈, 建章宫高五十丈。而这在赋家笔下己不是抽象的数字 显示, 而是具象的再现。

“于是左墄右平, 重轩三阶, 闺房周通, 门阉洞开。 列锤虐于中庭, 立金人于端闱, 仍增崖而衡阈, 临峻路而 启扉”, 班固《西都赋》中这段描述将栏杆重重, 台阶层 层的“高台”建筑风格描绘的淋漓尽致。扬雄《甘泉赋》写 宫中的通天台“是时未轃夫甘泉也, 乃望通天之绎绎。下 阴潜以惨廪兮, 上洪纷而相错。直嶢嶢以造天兮, 厥高庆 而不可乎弥度。”通天台高䇯如云, 已达天穹。就连地处 东鲁一方的灵光殿, 亦有“屹山峙以纡郁, 隆崛岉乎青云” 之雄姿。

汉代是建“阙”的盛期，往往成对出现，成为宫殿正门 前的一对角楼, 或者独立的两座高台, 四川雅安高弫墓阙 便是这个时代阙的代表，同样在汉赋中可见“阙”的身影。 王延寿《鲁灵光殿赋》中就有“朱阙岩岩而双立”的描述, 未央宫前亦有“树中天之华烕”，（《西都赋》）洛阳皇城 内“阙庭神丽。” (《东都赋》)

\section{4. 礼制与祭祀建筑的兴起}

东汉初年, 光武帝刘秀即位初, 推行“修文堰武”的政 策, 于是建三宫, 张衡《东京赋》: “乃营三宫, 布教颁 常。”作为帝王处理日常事务之场所, 修三雍（辟雍、明 堂、灵台的总称) 等文治礼教设施。明堂、辟雍和灵台是 重要的礼制建筑, 是东汉洛阳区别与西汉长安的标志性建 筑, 它们的修建, 是赋家笔下东都优于西都之处。利用这 些礼制建筑进行礼仪活动, 在明堂举行祭祀, 在辟雍举行 乡射、饮酒礼，在灵台辨云物、观休征。

张衡《东京赋》“然后宗上帝于明堂, 推光武以作 配。”造舟清池, 惟水泱決左制辟雍, 右立灵台。因进距 衰, 表贤简能。冯相观祲, 祈裭䘻灾。”班固《东都赋》
中云: “于是荐三牺, 效五牲, 礼神祇, 怀百灵, 觐明堂, 临辟雍, 扬缉熙, 宣皇风, 登灵台, 考休徵”。

不仅如此, 《东都赋》中还附上专门的《辟雍诗》《明 堂诗》《灵台诗》用以教化。西汉扬雄《甘泉赋》亦有针 对“圆丘”这一祭祀建筑“崇崇圆丘, 隆隐天兮”的说法。

\section{5. 缤纷的建筑色彩}

扬雄《甘泉赋》: “是时未轃夫甘泉也, 乃望通天之绎 绎。下阴潜以惨廪兮, 上洪纷而相错”, 通天台宏伟错综, 光辉灿烂。《鲁灵光殿赋》: “泪硙硙以璀璨, 赫燡燡而烛 坤”灵光殿光洁明亮, 杂彩之色映照大地; “葱翠紫蔚, 磥 硌瑰玮, 含光㫡兮”青紫相间, 参差错落, 绮丽珍奇。

宫殿多使用红色，《鲁灵光殿赋》中形容宫殿为“䑣 殁灵宫”，亦有“彤彩之饰，徒何为乎? ”上文中鲁灵光殿

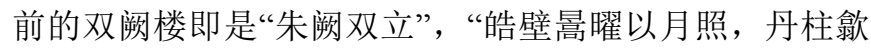
赩而电烻”, 白色墙壁, 红色立柱, 形成鲜明的色彩对比。

《西都赋》中形容未央宫为: “丰冠山之朱堂”, 同时形容 昭阳宫“玄墀扣砌, 玉阶䑣庭”, 《西京赋》形容昭阳宫则为 “䑣庭辉辉。”不仅如此, 宫殿还使用了黄铜和黄金装饰。 长安后妃宫室无处不是“金釭衔璧，是为列钱。“《西京赋》 中描绘的则是“金所玉阶”。《鲁灵光殿赋》形容其殿门为 “遂排金扉而北入”

\section{6. 华美的建筑装饰}

\subsection{1. 精湛的雕刻技艺}

汉代往往用梁柱的木面来雕刻图案, 能工巧匠精心打 造造就了汉代建筑精湛的雕饰艺术, 在汉赋中多有对其生 动的描绘。《甘泉赋》中形容其宫殿为“般倕弃其剞厥兮, 王尔投其钩绳”甘泉宫的建筑极尽精巧, 即使是公输班和 王倕这样的能工巧匠, 也只能放弃手中的工具, 自愧弗如。 人力是建不起如此壮观的宫殿的, 依靠鬼神的力量或许可 以建成。从一个侧面看出建造甘泉宫者技艺高超, 雕刻精 良, 非人力所能为也。

《鲁灵光殿赋》也用相同的描写手法感叹鲁灵光殿巧 夺天工, 工艺精湛。“穷奇极妙, 栋宇以来, 来之又兮。 神之营之, 瑞我汉室, 永不朽兮”, “非人通神之俊才, 谁 能克成乎此勋”, 同时《鲁灵光殿赋》中亦有对宫殿雕刻 艺术最为详尽的描述, 赋文所写殿内凡为木质结构之处, 无不雕刻着个性鲜明的形象, “云栥藻棁, 龙桷雕镂”, 无 处不是“飞禽走兽, 因木生姿”, 其内容之丰富, 几乎无所 不有, 猛虎相搏, 游龙蜿蜒, 飞鸟绕椽, 猿猴攀追, 仙人 往来, 玉女飘忽, 千姿百态, 栩栩如生。

\subsection{2. 精美绝伦的绘画}

汉代建筑将构建之上绘以图画, 赋予其文化意蕴, 建 筑因此而熠熠生辉。“帶倒茄于藻井, 披红菂之狎猎。”《西 京赋》写长安宫殿藻井之上绘有荷菱等彩色鲜明的图案, 屋椽上绘有耀眼的图案。最为精彩的是鲁灵光殿内的绘画。 “芝栭欑罗以践柏, 枝牚权枒而斜据”, 栌上绘有芝草; 藻 井上绘“反植荷薬。发秀吐荣, 菡舅披敷。绿房紫䓎, 窟 咤垂珠”; 斗拱以及梁短柱上描“奔虎篗拿以梁倚, 仡奋艮 而轩䯽。虬龙腾骧以蜿蟺, 领若动而喛跜”。其赋文云“图 
画天地, 品类群生。杂物奇怪, 山神海灵。写载其状, 托 之丹青。千变万化, 事各缪形。随色象类, 曲得其情。”

\subsection{3. 珠光翡翠的装饰}

班固《西都赋》中有云, “因瑰材而究奇”, 汉代宫殿 建筑己经大量地用珠玉、翡翠等珍贵材料来装饰宫室, 建 筑因此具有金碧辉煌, 华贵精致的特点。班固《西都赋》 中描述未央宫“雕玉瑱以居楹, 裁金璧以饰璫”, 对比张衡 《西京赋》形容未央宫“饰华滾与璧珰, 流景曜之韡晔”。 《鲁灵光殿赋》中亦有“骈密石与琅玕, 齐玉珰与璧英”的 描绘。《西都赋》写昭阳殿“翡翠火齐, 流耀含英, 悬黎 垂棘, 夜光在焉。于是玄墀扣砌, 玉阶彤庭, 礝磩彩致, 琳珉青苂, 珊瑚碧树, 周阿而生。”其中所列宝物, 皆为 天下珍奇。扬雄《甘泉赋》: “珍台闲馆, 琁题玉英, 蜵 蜎蠖濩之中”, 甘泉宫中还有用玉石雕制成的玉林犀牛和 马等物: “翠玉树之青葱兮, 璧马犀之瞵㻞”。

\section{7. 以自然美景来装点外部环境}

汉代建筑不仅在其空间、形态、结构、装饰等方面雄 浑威严、华美奢华, 还十分重视外部空间环境的营造, 在 宫殿内大多以树木、花草、假山、水系等自然美景来装点, 这已经成为汉人自觉的审美追求。张衡《东京赋》中说: “濯龙芳林, 九谷八溪。芙蓉覆水, 秋兰被涯渚戏跃鱼, 渊游龟蜼永安离宫, 脩竹冬青。阴池幽流, 玄泉洌清。” 灵台之内, “奇树珍果, 钩盾所职”。班固《西都赋》中描 述后妃居所“合欢增城, 安处常宁, 茞若椒风, 披香发越, 兰林草草，臽变飞翔之列。”张衡《西京赋》中亦云：“后 宫则昭阳飞翔，增成合欢，兰林披香，凤凰驾变”。灵光 殿更是追求“玄醴腾涌于阴沟，甘露被宇而下臻。朱桂䵢 亚于南北, 兰芝阿那于东西”的外部环境（王延寿《鲁灵 光殿赋》）。如此建构, 宫殿、门阙、楼台、池岛、树木、 花草, 清幽淡雅, 别有情趣。

\section{3. 汉赋中描绘的汉代都城营造特点}

西汉破秦灭楚, 开辟疆土, 以黄老道家之术治国, 修 养生息, 国力日益强盛, “至武帝之初, 七十年间, 国家 亡事, 非遇水旱, 则民人给家足, 则鄙凛庚尽满, 而府库 余财。京师之钱累百矩万, 贯朽而不可校; 太仓之粟陈陈 相因, 充溢露积于外, 腐败不可食。”[14]在这一时期, 城 市营造继春秋战国之后迎来了高潮。

\section{1. 两汉都城的选址}

\subsection{1. 西汉都城选址}

古代都城在选址时往往近水利而避水患, 接近河流且 地势要高, 在平原地区选择高处作为城址, 不仅如此, 古 人在城市选址过程中十分重视防御性, 多选易守难攻、通 道数量有限、便于控制与防御的地带开辟都邑。西汉长安 地区河流众多, 山川险阻, 防卫性好, 可谓定都之首选。 班固《西都赋》云: “汉之西都, 在于雍州, 定曰长 安。左据函谷二崤之阻, 表以太华终南之山。右界售斜陇 首之险, 带以洪河泾渭之川, 众流之隈, 汧涌其西。”
张衡《西京赋》中的描述则更为详细: “左有崤函重 险、桃林之塞, 缀以二华, 巨灵员局, 高掌远跖, 以流河 曲, 厥迹犹存。右有陇坻之险, 隔阂华戎, 岐梁汧雍, 陈 宝鸣鸡在焉。于前终南太一, 隆崛崔萃, 隐辚郁律, 连冈 乎嶓冢, 抱杜含户, 欱津吐镐, 爱有蓝田珍玉, 是之自出。 于后则高陵平原, 据渭踞泾, 澶漫靡迤, 作镇于近。其远 则九峻甘泉, 涸阴冱寒, 日北至而含冻, 此焉清暑。”

西汉长安土地肥沃上乘, 张衡《西京赋》中形容其“尔 乃广衍沃野, 厥田上上, 实为地之奥区神臬”, 这足以保 障都城日常及很长一段时间的物资供应。班固《西都赋》 中不仅描述其土地“华实之毛，则九州之上舆焉 ”，同时 “封畿之内, 厥土千里, 逴跞诸夏, 兼其所有”, 还形容其 长安周边“其阳则崇山隐天, 幽林穹谷, 陆海珍藏, 蓝田 美玉。商洛缘其郎, 䨋杜滨其足, 源泉灌注, 陂池交属。 竹林果园, 芳草甘木, 郊野之富, 号为近蜀, “物产丰饶, 佳果美玉, 应有尽有。因此除了考虑安全及防御之外, 城 市生活和经济的保障亦是都城选址的关键。

\subsection{2. 东汉都城选址}

班固《东京赋》形容东汉都城洛阳周围地形: “审曲 面势, 泝洛背河, 左伊右澱。西阻九阿, 东门于旋。盟津 达其后, 太谷通其前。回行道乎伊阙, 邪径捷乎轘辕。大 室作镇, 揭以熊耳。底柱辍流, 镡以大坏。”可见, 洛阳 城有可屏障之山川险阻, 以保都城之安全。同时洛阳地区 物产神奇“温液汤泉, 黑丹石缁。王鰖岫居, 能鳖三趾。”

（班固《东京赋》）

除了这一基本的选址观念之外, 东汉择都洛阳还有一 个重要原因就是它为“国土之中”。一直以来, “国土之中” 被认为是立都定国的理想地址。班固《东都赋》言: “迁 都改邑, 有殷宗中兴之则焉。即土之中, 有周成隆平之制 焉。”张衡《东京赋》云: “区宇义宁, 思和求中。点哲玄 览, 都兹洛宫。”所以, 择都洛阳恰恰符合了时人的“中国” 观。

\section{2. 城市规模宏大}

与春秋战国各诸侯国“各自为政”的城市营建不同, 汉 袭秦制, 旁倚秦咸阳旧城, 并利用部分旧离宫建造长安新 城。“当时长安城的面积约为公元 4 世纪罗马城的 2.5 倍” [15]。不仅如此, 为加强政治大一统及中央集权, 管理 封地贵族豪绅, 在长安城郊帝陵处设陵城, 尤以北区五陵 最为显贵, 形成了拱卫京师的城市群, 所谓“若乃观其四 郊, 浮游近县, 则南望杜霸, 北眺五陵, 名都对郭, 居邑 相承。”(班固《西都赋》)

\section{3. 城市结构与布局}

\subsection{1. 城市结构}

西汉初年旁倚秦咸阳旧城, 并利用部分旧离宫建造长 安新城, “汉氏初都, 在渭之涘, 秦里其朔, 实为咸阳” (张 衡《西京赋》), 且北面靠近渭水, 故而城市布局不规则, 据记载, 城内向北出横门有外郭, 向东出 3 座门亦有外郭, 班固《西都赋》中云: “建金城而万雉, 呀周池而成渊。” 
《西京赋》中载: “于是量径轮, 考广衰, 经城洫, 营郭 郛。”这说明长安城外有护城河围绕, 恤外有郭城。

\subsection{2. 城市布局}

中国古代都城的营造，大多遵循战国时成书的《考工 记》中记载之法则, 张衡西京赋中有云: 西汉都城长安的 营造, 不仅“览秦制”, 亦“跨周法”, “狭百堵之侧陃, 增九 筵之迫胁。”所谓的“周法”, 正是时人遵循《考工记》之 原则来营建都城。

关于东汉都城洛阳的营建模式, 汉赋中的描述则更为 详尽, 班固《东都赋》: “然后增周旧, 修洛邑, 扇巍巍, 显翼翼。光汉京于诸夏, 总八方而为之极。是以皇城之内, 宫室光明, 阙庭神丽, 奢不可逾, 俭不能侈。外则因原野 以作苑, 填流泉而为沼, 发蘋藻以潜鱼, 丰圃草以毓兽。 制同乎梁邹，谊合乎灵直。”这里的“周旧”、“制同”、“谊 和”成了东都洛阳的营造原则, 在东汉人的理解中, 即《考 工记》中所述“匠人营国。方九里, 旁三门。国中九经九 纬, 经涂九轨, 左祖右社, 面朝后市, 市朝一夫”之准则。 张蘅《东京赋》亦有: “周公初基, 其绳则直。茩弘魏舒, 是廓是极。经途九轨, 城隅九雉。度堂以筵, 度室以几。 京邑翼翼, 四方所视。汉初弗之宅, 故宗绪中圮”之说。

\section{4. 两汉都城功能分区明确}

两汉都城内的区域由街道分隔开, 从汉赋来看, 主要 有宫殿区、居住区以及商业区。

西汉长安先后建造几处宫殿, 分别分散在城的西南部、 东南部和城西, 班固《西都赋》云: “前乘秦岭, 后越九 曼, 东薄河毕, 西涉岐雍, 宫馆所历, 百有余区。”西汉 未央宫位于龙首原上, 是长安城中地势最高之处, 向北靠 近渭水地势渐低, 布置着北宫、桂宫、明光宫及市场和居 民问里, 这也符合古人一般的城市营造观念, “疏龙首以 抗殿, 状巍峨以苃嵄。”(张衡《西京赋》)

汉代城市皆为里坊制, 城市居民居住点以里为单位, 《西都赋》云: “内则街衙洞达, 闾阎且千。”“里”四周筑 有围墙, 问为里之门, 阎为里中之门, 里门设有门监。又 《西京赋》云: “原里端直, 夢宇齐平。北成甲第, 当道 直启。”城市的商业区称市。长安城大街东西两侧分布 9 个 市场, 班固《西都赋》云: “九市开场, 货别隧分。”张衡 《西京赋》记: “尔乃廓开九市, 通圖带圆。”

\section{5. 城市内部交通}

汉代都城内部交通体现在汉赋中, 主要是街道、城门、 城外道路等, 据记载, 西汉长安场每面皆有 3 城门, 城街 道有“八街”“九陌”。现经考古证明, 长安城内的八条主干 道通向城门, 每条大街分成3条并列的道路, 用排水沟分 隔开来, 中间为皇帝专用的驰道。《西都赋》中云: “批 三条之广路, 立十二之通门。”《西京赋》亦云: “徒观其 城郭之制, 则旁开三门, 参涂夷庭, 方轨十二, 街倠相经。”

\section{6. 两汉都城城市人口增多, 经贸繁荣}

在这一时期, 城市人口数量增多, 汉代城市人口大约 占总人口的 $40 \%$ 左右, 正如《西都赋》中描述: “于是既
庶且富, 娱乐无疆。都人士女, 殊异乎五方, 游士拟于公 侯, 列肆侈于姬姜。乡曲豪举, 游侠之雄, 节慕原尝, 名 亚春陵。连交合众, 骋水乎其中。”由于汉代城市流动人 口增多, 城市蓬勃发展, 城市经济也竞相繁荣, 商业交流 频繁, 班固《西都赋》中载长安城中 9 个市场开市之后: “人 不得顾, 车不得旋, 阗城溢郭, 旁流百原, 红尘四合, 烟 云相连。”

\section{4. 结论}

建筑作为汉赋的主要表现领域, 所描绘的一幅幅生动 的都市和建筑画卷, 远远超过了文献史料, 前人不论是研 究汉代都城还是汉代建筑, 无不引用汉赋的文字加以佐证, 普罗大众也只有从汉赋的描写中来欣赏汉代建筑的风貌。 汉代辉煌的建筑文化为汉赋提供了许多建筑实物作为刻 画对象, 可以说正是有了辉煌的汉赋建筑文化, 才使得汉 赋的内容得到了充实, 题材得到了扩大, 艺术技巧得到了 提高, 开拓了一片新的天地。

\section{参考文献}

[1]［唐]姚思廉撰.《梁书》卷三十五《萧子显传·自序》.

[2] [清]王国维.宋元戏曲史·自序[M].北京:团结出版社, 2006:1.

[3] 田胜利, 汉赋中长安、洛阳建筑名物命名的文化义涵选释 [J].人文杂志，2020,(12).

[4] 章沧授, 论汉赋对建筑文化的阐释[J]. 安庆师范学院学报(社 会科学版),2001,(05).

[5] 周显, 汉赋中的建筑认知[D]. 浙江大学硕士论文, 2013.

[6] 邱杨琰, 从汉代京都赋看两汉都城建筑文化[D]. 苏州大学硕 士论文, 2009 .

[7] 处风华.汉代风俗文化与汉代文学[D],山东大学, 2007.

[8] 贡小妹, 两汉建筑赋的环境描写[]].东岳论丛,2002,(02).

[9] 龙坚毅, 汉赋与汉代社会文化[D].厦门大学博士论文, 2007.

[10] 费振刚, 胡双宝, 宗明华. 全汉赋[M].北京大学出版社,1993.

[11] 刘敦祯, 中国古代建筑史[M].中国建筑工业出版社, 1993.

[12] 李允鉩, 华夏意匠: 中国古典建筑设计原理分析 [M].天津: 天津大学出版社,2005.

[13] 乐嘉藻, 中国建筑史[M].团结出版社, 2005.

[14] 《前汉书》卷二四上《食货志上》。

[15] 潘谷西.中国建筑史（第七版） [M].北京:中国建筑工业出版 社, 2015. 